\title{
The Implications of Psychological Skills on the Effectiveness of the Athletic Performance Among Boxing Athletes in Jordanian Boxing Clubs
}

\author{
Dr. Nashwan Abdallah Abedalqader Nashwan \\ University of Isra'a- Amman- Jordan
}

\begin{abstract}
This study aimed to identify the nature of the relationship between psychological skills and the effectiveness of skill performance characteristic among boxers in selected Jordanian clubs. The study population included boxing athletes in the clubs of the Jordan Boxing Federation, which amounted to 11 clubs and centers. While the study sample was chosen by the deliberate method where the number of the study sample reached 65 athletes. The researcher used Mental Skills Questionnaire includes six dimensions: the ability to mental perception, the ability to focus attention, self-confidence, the ability to confront anxiety, the ability to relax, and achievement motivation. In addition to use a set of standardized tests for the special kinetic skills of boxing, as follows: Kinetic sped of the boxing arms, the strength stretching of the arm muscles in boxing until fatigue, agility kinetic boxing test, and attention Focus Meter for boxers. The study revealed that there is a positive significant relationship between the dimensions of psychological skills and the kinetic speed of the boxing arms, stretching arms muscles in boxing until fatigue, agility kinetic boxing test, and attention focus meter for boxer.A set of recommendations were made, includes: interest in the psychological aspect, being one of the basic requirements that affect the athletic performance of a boxer, and conducting periodic tests for boxers in successive periods to find out the true level of mastery of performance, physical fitness and knowledge of boxing motor skills.
\end{abstract}

Keywords: Psychological skills, Effectiveness, Athletic performance, Boxing, Jordanian boxing clubs

DOI: $10.7176 / \mathrm{JEP} / 11-36-14$

Publication date: December $31^{\text {st }} 2020$

\section{Introduction}

Psychological skills are considered one of the important and basic fields in sport, as achieving high levels in various sports activities, including boxing, is linked to sports training for a game includes multiple and varied punches, this makes the boxer really need to diversify his punching performance, which requires From him more effort (Anastazi,1972).

Sports studies indicate the importance of the psychological factor and its positive impact on sports performance. (Loehr,1994) showed that psychological skills that reflect mental toughness contribute by no less than $(50 \%)$ to achieving sports achievement.

(Gould et al.,2004) emphasized that the psychological factor is the most important in sport achievement, while (Middleton et al.,2004) argued that psychological skills give athletes stamina compared to their competitors during sports competition, by developing focus, confidence, and steadfastness under pressure.

(Ray,2003) pointed out that psychological skills are the ability to stabilize the ideal performance when competition pressures intensify, this requires good technology and mental skills, in addition to the fact that the instability of performance during competitions is primarily attributed to psychological variables, which come in the forefront of mental hardness variables. Taking into account that mental toughness is an acquired trait outside of genetics.

(Lefkowits, et al.,2003) argued that psychological skills are related to a physical and emotional aspect, it is not that you have the instinct to crush your competitors or be characterized by coldness, but they mean reaching the ideal and maximum performance of your skills, regardless of the circumstances of competition. Psychological skills problems can be easily discovered in the sports field, as it appear clearly either through the athletes talking a lot with the coach, or through a lot of grumbling, objecting and blaming teammates, as a result of the athlete's impact on the surrounding circumstances of atmosphere, judgment and audience, and by getting to know these Behaviors and their follow-up, we can figure out the hardness of psychological skills of athletes and the team.

Since sports training and physical or psychological tests are related to sports sciences, and affect the athlete's physiology that lead to internal and external changes, the progression of a boxer's athletic level depends on the extent to which he responds to those changes that occur outside and inside the body's systems. One of the most important functional variables is the pulse rate and its speed after each round, and blood pressure, this in turn affects the effectiveness of the skillful performance on which the boxer depends and resolving the outcome in his favor.

Boxing requires a high effort to perform the punches and counter them, this will lead to changes that may affect the course of the fight in favor of the boxer either in poor or good performance (Pehazur \& Schmelkin,1991). 
The basic skills of boxers are positively affected in the event of an increase in the level of good psychological preparation which makes the movement performance characterized by strength, vitality and speed required for different playing situations, as all these qualities and abilities are considered among the main factors to achieve better sports achievement, raise the level of this game, and raising the level of athletes (Crust \& Cloygh, 2005).

(Allawi, 1998) points out that the psychological dimensions are one of the important requirements to reach high levels in various activities, as most athletes at the advanced level converge to a large degree in terms of physical, skill and planning level, and as a result, there is an important factor that determines their struggle during Sports competitions for the sake of victory, which is the psychological factor that is closely related to the personality through its correlation with the subject of self-confidence, the ability to confront anxiety, perception and focus, and the motivation to win.

\section{Statement of purpose}

The progression of a boxer's athletic level depends on the extent to which he responds to the changes that occur outside and inside the body's systems through the process of skill tests and their effectiveness to reach the state of athletic achievement. The process of developing punching skills during fights, training work, and the ability to achieve distinguished skillful and psychological performance in order to reach the desired goal.

Through the researcher's experience in boxing, in addition to his specialization in sports psychology, he noticed that the level of some punching teams was quite modest, as those teams did not achieve the required athletic level due to the weakness of their physical and skillful side, due to the interest of some coaches in aspects. Physical, skill and planning and not focusing on the psychological aspect, including psychological skills, in their training units, despite the importance of these skills in the psychological preparation and the integrated skills of the athletes to reach high level.

Accordingly, the researcher undertook this study, which aims to identify the nature of the relationship between psychological skills and the effectiveness of skill performance characteristic of boxers, which may contribute to benefit from psychological preparation programs to increase and improve their athletic skills that affect a high degree in their sports performance.

\section{Significance of the study}

This study is highlighted by analyzing the correlational relationship between the dimensions of psychological skills and some basic physical skills of advanced boxers, as psychological skills are no less important than physical skills, as the latter is the distinguishing mark between boxers in achieving success and upgrading performance to the level of achievement or distinction. This shows the importance of training in psychological skills along with physical exercises; being the difference in appearing at a better level.

\section{Objectives of the study}

This study aims to identify the correlational relationship between the level of psychological skills dimensions and the level of performance of some physical skills for selecting boxing athletes for Jordan Boxing Clubs.

\section{Hypothesis of the study}

This study starts from the main hypothesis that: There are significant differences between psychological skills dimensions and the effectiveness of skill performance in regarding with selecting boxing athletes for Jordanian Boxing Clubs.

\section{Limits of the study}

0 Spatial Borders: A selection of boxing clubs in Amman- Jordan, namely: Smart Fitness, Al Amjad Center, Al Majd Center, Al Asif Center, Top Gym Center, Black Belt Center, Al Shoala Club, Al Baqa'a Club, and Jordan Youth Center.

0 Temporal boundaries: the period from 6/10/2019 to 20/12/2019.

\section{Concepts of the study}

0 Psychological skills: Organized educational programs designed to provide assistance for both athlete and coach with the purpose of improving and mastering performance, as well as making sporting practice a source of enjoyment (Fawi, 2006).

The researcher defines psychological skills procedurally as the skills related to the psychological aspect of the boxer, which are related to the achievement of skillful and physical performance, the boxer can use them according to the conditions of the competitive or training position.

0 Skillful performance: the athlete's performance of all sports skills related to the practicing activity (Nashwan, 2010), the researcher defines it procedurally as the ability of the boxer to perform all the motor 
skills required by the sport of boxing.

0 Boxing: also called the sport of kings or the noble art. Boxing is a sport in which two athletes of similar weight attack each other with their fists in a series of periods ranging from one to three minutes called "rounds". This sport is based on avoiding the opponent's punches and trying to punch him (Nashwan, 2018).

0 Mathematical psychological test: A standardized exercise designed to measure a certain dimension, it is a tool used to collect information for the purpose of evaluation (Falchinili, 1986).

The researchers define it procedurally as a systematic, standardized method designed to compare the behavior of a group of boxers.

\section{Theoretical framework and Literature review}

There has been a growing interest in determining the relationship between the physical, skill and planning aspects of training and the psychological aspect, it has been concluded that reaching high levels of sports requires the athletic to use his physical, skill, written and psychological capabilities in an integrated manner, in order to provide the best possible performance (Nashwan and Arab, 2017 ).

Psychological skills are considered one of the most important topics closely related to the personality of the boxer, which can be identified through sports competitions, which are considered the real test of the physical, skill and psychological abilities of the boxer, given that the competition includes a set of various situations that necessitate the boxer positive adaptation with Competitors, referees, and fans (Guidetti et al., 1997), the superior athlete possesses a positive behavior enables him to face the conditions and pressures of competition, while the reluctant athlete needs psychological training to raise the level of his competitive behavior (James et al., 2002).

Psychological skills include a range of dimensions, the researcher will be limited to the dimensions of: the ability to mental perception, the ability to focus attention, self-confidence, the ability to confront anxiety, the ability to relax, and the motivation of athletic achievement.

\section{Ability to Mental perception}

Mental perception is one of the short-term psychological preparation processes, it is based on training the athlete to embody a competitive or training situation that has not previously occurred in his mind while linking this situation with the feelings and emotions that can occur (Fulghan,2004).

Mental perception represents a mental psychological skill. It can be acquired by programming the athlete's mind to respond to events that he previously experienced in similar previous situations (Porter, 2003), that is, the mental perception is to evoke the memory of stored events from the reality of past experience, and the possibility of modifying them and producing new images and ideas (Gorden,2004).

Among the most important advantages of mental perception is that it speeds up the process of learning motor skills through the strategy of mental recall for the correct and better movement, in addition to the contribution of mental perception in developing a performance training plan before the start of the competition, which contributes to making better decisions during it (Pichard,2002), some studies have indicated that mental perception contributes to controlling the physiological responses that a athlete can perceive, such as heart rate, blood pressure, breathing, and skin temperature. As it is through mental perception that the athlete can recall some of the previous situations that provoked his anger and led to his physiological arousal, and work to visualize them positively to reduce the physiological emotions that he will be exposed to in similar future situations (Khasky \& Smith, 1999).

\section{Ability to focus attention}

Focusing attention is the next step for attention that is inseparable from it, attention means: "The individual chooses one variable, and isolates the other variables to which he is exposed (Stevens,2002), there are several types of attention concentration that can be classified into what follows (Nashwan \& Dalala'ah, 2020):

1. Narrow focus Attention: where the athlete is alert or aware of one thing or a relatively small area, this is evident in the sport of archery or shooting a basketball athlete or football on the goal.

2. Broad Focus Attention: by gathering ideas and fixation of attention to achieve a goal.

\section{Self confidence}

Self-confidence is the athlete's realistic expectation of success (Desterch,1975), that is, the athlete's expectation of the realistic things that must be done to win, which is the athlete's feeling that his performance will be good regardless of the results even if the opponent is outperforming him (Shmidt \& Wriberg, 2008).

Self-confidence has a great importance, which is evidenced by the following points (Hayley, 2004):

1. Achieve psychological harmony and contentment.

2. Help in gaining experiences, as self-confidence is a motivation for the athlete, and it gives him a desire to acquire new skills.

3. Success in work through the athlete's belief in his abilities. 
4. Facing any problems or difficulties that the athlete goes through.

5. Stirring up positive emotions through the athlete's sense of vitality, enthusiasm, pleasure and satisfaction, which leads to the fluidity, strength and speed of his skillful performance.

6. Helping athlete to relax and maintain calm, especially during the articulated situations in the competition.

\section{Ability to confront anxiety}

Anxiety is considered as most important psychological emotions that affect the performance of athletes, and this effect may be either positive, pushing them to exert more effort, or negatively affecting performance (Thomas \& Forgaty, 1997).

Anxiety is defined in the sports field as: "A psychological state that dominates the athlete, it is characterized by fear and ambiguity (Nashwan, 2010). Coach could figure the level of anxiety among athlete by supervise their behavior, such as failure to abide by the planning duties and forgetting them during competition, or the athlete's tendency to claim that he was injured (Sellars,1997).

There are two types of anxiety among athletes, namely: physical anxiety and cognitive anxiety. As for physical anxiety, its presence in the athlete can be inferred through several manifestations, such as: increased sweating and increased heart rate, while the manifestations of cognitive anxiety are represented by an increase in unwanted negative thoughts (Fourie \& Portgielter,2001). The researcher believe that it is necessary to deal with the cognitive anxiety of the athlete; due to it's clearly affects to the mental processes, which negatively affects the physical and motor performance of the athlete.

\section{Ability to relax}

Relax is a temporary and deliberate withdrawal from activity; it allows recharging and full utilization of physical, mental and emotional energies (Nashwan,2010). Relaxation is characterized by the absence of activity and tension, which is a period of inactivity and the neglect of the senses and the best state of relaxation that the individual can reach is called the level of zero arousal and there is a difference between individuals in this case (Lowther,2002).

Meditation contributes in removing tension from the body and relaxing it through muscle contraction and relaxation. It is one of the best methods that are appropriate for the sports field. It ranges from four to six seconds during which a large group of fibers contract and the sequence of contraction leads to a high degree of relaxation of the entire muscle (Nashwan \& Arab,2017).

Thus, the muscles of the body can reach a better stage of relaxation through the use of steady contraction in this way, if relaxation is practiced daily for two or three weeks, the individual will be able to relax specific muscle groups (James et al,2002).

Relaxation skills help reduce anxiety, tension and control anger at times. Stress; in order for relaxation to become a natural response to stress, it is necessary to take advantage of all available opportunities for relaxation training (Lefkowis et al,2003). Relaxation opposite to tension" which is a state of relaxation with the absence of strong emotions (Lowther,2002).

The importance of training relaxation skills lies in the following aspects (Ray,2003):

1. Contribute in reducing the athlete's levels of stress and anxiety, whether before, during, or after the competition

2. The ability to reduce the level of muscle activity or muscle tension under any circumstances.

3. The ability to control the level of muscle or emotional arousal.

4. Helping to reach high levels of psychological comfort, calm and reassurance

5. Awareness of the essential differences between relaxation and contraction or muscle tension.

6. Increase ability to acquire some types of motor perceptions.

7. Getting rid of some muscle tensions in certain muscle groups according to the athlete's desire.

8. Contribute to the delay in the onset of fatigue and the speed of recovery from physical or mental exertion.

9. Overcome insomnia that may accompany the athlete on the night of competition.

10. Acquiring pleasant positive emotions.

11. Gain the ability to control vital and life responses such as heart rate, body temperature, electrical activity on the skin surface, or other vital responses.

In sports field, relaxation can be used for the following (Nashwan \& Arab,2017):

1. Before the warm-up phase, so that the athlete is aware of his physical, psychological and mental condition.

2. After learning a new skill.

3. To reach the calm down situation.

4. Before practicing mental perception.

\section{Achievement motivation}

Motives are internal physical and psychological states that provoke behavior in certain circumstances continuously 
until it ends to a specific goal, as it stimulates the activity and determines its direction to achieve a specific goal (Anastasi,1972). They are the sum of process of stimulating and moving the behavior or action and reinforcing the activity, organizing it and directing it towards the goal (Thomas \& Fogarty,1997).

Motivation denotes the dynamic relationship between the individual and the surrounding environment, as it is the one that stimulates the behavior and pushes the individual to do a specific action to remove the tension and satisfy the need (Prichard,2002). The motivation function has two aspects, namely: activate the behavior, and directing it towards a specific goal (Lefkowits et al.,2003).

There is a strong relationship between activating the behavior and directing it. Where activating the behavior means the individual's attention to a certain thing that leads to the achievement of the goal, while direction means continuing the activity or behavior towards the goal and maintaining that direction until the goal is achieved (Middeton et al.,2004).

The concept of motivation is used to refer to what prompts an individual to undertake a behavioral activity, to direct this activity towards a specific destination (Lowther,2002). Most people assume that the behavior is functional, that is, that the individual practices a certain behavior because of the results or consequences of this behavior that satisfy some of his needs or desires, and this fact may be the postulate that underlies the concept of motivation, as this concept refers to internal emotional states, And to processes that incite, direct and maintain behavior. Although it is impossible to directly observe motivation, it is a basic concept of educational psychology, which can be deduced by observing the behavior of individuals, and by observing the environment in which this behavior takes place in its context (Khasky \& Smith,1999).

In view of the important role that motivation plays in learning and performance, psychologists determined the factors affecting it, dividing motivations into two large categories, the category of Biological motives, which are motives resulting from various physiological needs, such as hunger, thirst, sex, rest and sleep, etc., and the social motivation category, which are the motives resulting from interaction with the social environment, such as the need for belonging, security, achievement, self-esteem, self-realization, etc. (Nashwan,2010).

\section{Literature review}

0 Thomas \& Fogarty,1997 argued the effect of using mental perception, training on talking to oneself, training on psychological skills and performance levels, the study sample consisted of (23) golf athletes, to whom a questionnaire was distributed that includes five psychological skills, which are negative thoughts, mental preparation, motor mechanism, and performance. In addition, a mental training program was applied to the sample for a period of (8) weeks. The study revealed that the compatibility between mental perception and conversation with the self contributes to improving performance in golf, in addition to the psychological factors associated with sports performance and participation in units mental training is of great importance in the foundation of general training.

0 Guidetti et al, 1997 focused on the relationship between physiological factors to the performance of boxers in average weight, the study sample consisted of (8) boxers from the elite Italian amateur boxers. The researchers used the descriptive approach and some measurements were taken over two weeks, in the first week some anthropometric measures were taken (fat percentage, arm length and capacity), in the second week a measurement was performed Vo2, lactic percentage, grip strength, maximum heart rate, and anaerobic threshold. The results indicated that there are two types of basic factors related to performance in boxing, which is physical fitness as indicated by the anaerobic threshold and the limit maximum consumption of oxygen and the upper body is referred to as grip strength.

0 Alhasany,2003 identified the effect of a mental training program on the level of performance of the front somersault skill, the study sample consisted of (40) female students of the third year, majoring in gymnastics, and the physical skill tests were used, the cardiograph levels card, the mental perception scale, and the response scale Emotionality, and the Seshor test of musical abilities. The study found an effective effect of the mental program for ulcers in improving the motor rhythm, level of skill performance and emotional stability for students, in addition to the presence of a role for the proposed mental program in developing the skill of relaxation and mental perception.

0 Ahmad,2004 built a scale of schematic thinking for emerging boxers to identify the relationship between schematic thinking and some psychological skills and the effectiveness of competitive skill performance among boxers, the study sample may be (40) boxers under the age of (17) years of junior boxers registered in the Egyptian amateur boxing Federation for a season 2002/2003, the study found a significant correlational relationship between linear thinking and some psychological skills of boxers, and the existence of a significant correlation between linear thinking and the effectiveness of competitive skill performance among boxers.

0 Atowi,2017 identified the level of psychological skills and competitive behavior and the relationship between some psychological skills (self-confidence, mental perception, and relaxation) with competitive 
behavior among football athletes. The study sample consisted of (40) athletes from the Algerian football teams, the category of cubs. The study concluded that there was a positive correlation between psychological skills and competitive behavior among soccer athletes, and the study recommended that coaches pay attention to developing the psychological answer to athletes because of its important role in improving their competitive behavior.

The current study benefited from previous studies in building its theoretical framework, and identifying psychological skills that affect athletic performance. This study is distinguished from other previous studies in the following points:

0 Study population and sample, as this study was applied to Jordanian club boxers, which was not covered by any of the previous studies.

0 Dimensions of psychological skills, as this study dealt with the dimensions of psychological skills, such as the ability to mental perception, the ability to focus attention, self-confidence, the ability to confront anxiety, the ability to relax, and achievement motivation.

0 The training program, where the researcher developed a training program based on psychological skills in its six aforementioned dimensions.

\section{Methodology}

The researcher relied on the descriptive approach using the survey method, as it is the most appropriate approach to the nature of this study.

\section{Study population and it's sample}

The study population included boxing athletes in the clubs of the Jordan Boxing Federation, which amounted to 11 clubs and centers.

The study sample was chosen by the deliberate method from the study population, where the number of the study sample reached 65 athletes from the clubs: Smart Fitness, Al Amjad Center, Al Majd Center, Al Asif Center, Top Gym, Black Belt Center, Al Shola Club, Al Baqa'a Club, and Jordan Youth Center.

\section{Psychological Skills Dimensions Test Scale}

It is called the Mental Skills Questionnaire, which was designed by Stefan Bull, Christopher Shambrook, and John Albinson (1996) to measure some important mental (psychological) aspects of mathematical performance, and it includes the following dimensions (Allawi, 1998):

0 The ability to mental perception.

0 The ability to focus attention.

0 Self-confidence.

0 The ability to confront anxiety.

0 The ability to relax.

0 Achievement motivation

This test includes (24) phrases, each of the six dimensions previously explained is represented by (4) phrases, and the athlete answers the test statements on a six-degree scale:

- The ability to mental perception includes phrases $(1,7,13,19)$, all of which are positive expressions except for the phrase (13) in the opposite direction of the dimension.

- The ability to focus attention includes phrases $(3,9,15,21)$, all of which are phrases in the opposite direction of dimension.

- Self-confidence includes phrases $(5,11,17,23)$, two statements $(5,17)$ in the direction of the dimension and $(11,23)$ in the opposite direction of the dimension.

- The ability to confront anxiety includes phrases $(4,10,16,22)$, all of which are phrases in the opposite direction of the dimension.

- The ability to relax includes phrases $(20,2,8,14)$, all of which are positive expressions except for the phrase (8) in the opposite direction of the dimension.

- Motivation achievement includes statements $(6,12,18,24)$, all in the direction of the dimension.

Athlete answers the six-degree scale and the number (1) indicates that the phrase does not apply completely, the number (2) indicates that the phrase applies a very small degree, the number (3) a small degree and the number (4) with a moderate degree, and the number ( 5) To a large degree, and the number (6) indicates that the phrase applies very large extent, these degrees are towards the dimension, and the negative expressions are on the contrary, the scores for each dimension are summed separately as the lower degree (4) and the greater degree (24) and the more the degree approaches or exceeds the hypothetical mean, which is (14) for each dimension, the more it is distinguished by the characteristic that this dimension measures, and the lower its degree, this indicates the need 
to acquire more training on this mental skill that this dimension measures, and the lower degree of the scale is formed as a whole (24), the major degree (144), the hypothetical mean is (84).

\section{Specification of the used tests}

The researcher approved a set of standardized tests for the special kinetic skills of boxing, as follows:

0 Kinetic speed of the boxing arms: testing the largest possible number of various punches on the punching bag for a period of (10) seconds of movement. The purpose of the test is to measure the kinematic velocity of the arms, where the boxer stands in front of the bag in the grooming position, and upon hearing the coach's signal, the boxer begins punching the bag using various punches as many as possible within (10) seconds, with the performance being photographed by the camera at a height of 1.9 meters, the camera is at the opposite angle to the boxers, so that the boxer is seen very clearly when the photography is shown to the orthodontist for the purpose of recording only the correct punches with a special form for recording. Correct punches are recorded on the laboratory's punching bag within (10) seconds.

0 Stretching arm muscles in boxing until fatigue. The purpose of the test: to measure the strength elongation of the muscular muscles of the arms, where the boxer punches the bag upon hearing the start signal until fatigue with photographing the performance by the camera, which is $1.9 \mathrm{bar}$, and is (2) high. The camera is in the opposite angle to the boxers, so that the boxer is clearly seen when the shooting is shown to the expert to record only the correct punches with a special form.

$0 \quad$ Agility kinetic boxing test: to measure agility with boxing. Where the boxer faces a bag No. (1) attached to the center of the ring, upon hearing the start signal, he performs a touch on the bag and then moves back to a bag No. (2), leads one touch on the bag, and then moves by leap Punching No. (3) to lead one touch, then he moves forward by jumping to the punching bag No.(1) attached to the center, the boxer performs one touch, and then moves by leaping forward to bag No. (4) leading to the left with one left. To the punching bag No. (5), the boxer performs one touch, and then moves backward to the punching bag No. (1) to perform one touch. The expert records the time.

0 Attention Focus Meter for boxers: to measure the concentration of attention of boxers. The device consists of a rubber cone at the top of a speaker, and a base made of wood is installed at the bottom, it contains inside a speaker amplifier for sound, and an MP3 speaker is installed on the wooden base connected to the amplifier and external speaker, the device also contains a transformer External and resistors protect the device from damage, and it can operate in two ways: (the battery, the electric current), and the instructions are issued via (RAM) programmed to (30) different (time rhythm sound) tones in addition to a starting tone, an end bell. As for the gelatinous doll, it is made of a flexible gelatinous material designed for boxing, fixed on a thick base that is filled with sand or water, and contains a spring that can be tilted in four directions. The boxer stands opposite the gelatinous doll in the appropriate preparation position for him, the speaking person next to the doll is at a distance of one meter, he issues random prompts in the form of different numbers from (1-4), the time spent between an instruction and another is one second, for a period of (30) second.

\section{Discuss the results of the study}

Display the results of means and standard deviations of the study variables:

Table No(1).

Mean and standard deviations of the dimensions of psychological skills after applying the special motor skills (Attention-boxing focus measurement test - Boxing Arm Muscles strength extension to fatigue Kinetic velocity of boxing arms - Boxing agility test

\begin{tabular}{|l|l|l|}
\hline Psychological skills dimensions & Mean & Standard deviation \\
\hline Ability to mental perception & 1.65 & 1.333 \\
\hline Ability to focus attention & 1.46 & 1.201 \\
\hline Self confidence & 1.69 & 2.321 \\
\hline Ability to confront anxiety & 1.68 & 2.001 \\
\hline Ability to relax & 1.43 & 1.330 \\
\hline Motivation of athletic achievement & 1.57 & 1.980 \\
\hline
\end{tabular}

It is noticed from table No. (1) that the arithmetic meanings of the dimensions of psychological skills after applying special motor skills (Attention-Boxing Focus Measurement Test - Strength Elongation of the Arm Muscles in Boxing to Fatigue - The Kinetic Velocity of the Two Arms in Boxing - Boxing Agility Test has reached (1.56) for the dimension of the ability to mental perception with a standard deviation of (1.333), the arithmetic mean of the dimension of the ability to focus attention was (1.46) with a standard deviation of (1.201), while the self-confidence dimension was (1.69) with a standard deviation (2.321), the arithmetic mean of the ability to 
confront Anxiety (1.68) with a standard deviation of (2.001), the mean of the dimension of the ability to relax is (1.43) and the standard deviation of (1.330), finally, the arithmetic mean of the dimension of motivation for achievement is (1.57) and the standard deviation was (1.980).

Table No(2)

The results of a matrix of correlation between psychological skills and the effectiveness of skill

performance (the test of concentration of attention for boxers - strength extension of the muscles of the arms in boxing to fatigue - the motor speed of the arms in boxing - the test of agility in boxing)

\begin{tabular}{|l|l|l|l|}
\hline Basic skills in boxing & measuring unit & Mean & $\begin{array}{l}\text { Standard } \\
\text { deviation }\end{array}$ \\
\hline Measure the focus of attention for boxers & Per minute & 1.88 & 1.777 \\
\hline $\begin{array}{l}\text { Stretches of strength for boxing arm muscles until } \\
\text { fatigue }\end{array}$ & Per punches & 1.98 & 1.222 \\
\hline The kinetic speed of the two arms in a box & Per second & 1.44 & 1.088 \\
\hline Kinetic Agility Test & Per minute & 1.66 & 0.266 \\
\hline
\end{tabular}

The results of Table No. (2) indicate that the arithmetic mean for measuring the focus of attention for boxers reached (1.88), with a standard deviation (1.777), while the arithmetic mean of the strength elongation of the muscles of the arms in boxing until fatigue reached (1.98), with a standard deviation (1.222), the mean reached the arithmetic of the kinetic velocity of the two arms in boxing is (1.44) with a standard deviation (1.088). As for the agility test for boxing, its arithmetic mean was (1.66) with a standard deviation $(0.266)$

Table No(3)

Correlation values for the boxing psychomotor and psychomotor skills dimensions

\begin{tabular}{|c|c|c|c|}
\hline Special motor skills & Psychological skills & $\begin{array}{c}\text { Computed } \\
\text { correlation } \\
\text { values }\end{array}$ & Significance \\
\hline \multirow{6}{*}{$\begin{array}{l}\text { Measure the focus of } \\
\text { attention for boxers }\end{array}$} & Ability to mental perception & 0.456 & Statistically significant \\
\hline & Ability to focus attention & 0.789 & Statistically significant \\
\hline & Self confidence & 0.758 & Statistically significant \\
\hline & Ability to confront anxiety & 0.903 & Statistically significant \\
\hline & Ability to relax & 0.751 & Statistically significant \\
\hline & Motivation of athletic achievement & 0.821 & Statistically significant \\
\hline \multirow{6}{*}{$\begin{array}{l}\text { Stretching arms } \\
\text { muscles in boxing } \\
\text { until fatigue }\end{array}$} & Ability to mental perception & 0.714 & Statistically significant \\
\hline & Ability to focus attention & 0.259 & Statistically significant \\
\hline & Self confidence & 0.811 & Statistically significant \\
\hline & Ability to confront anxiety & 0.870 & Statistically significant \\
\hline & Ability to relax & 0.524 & Statistically significant \\
\hline & Motivation of athletic achievement & 0.702 & Statistically significant \\
\hline \multirow{6}{*}{$\begin{array}{l}\text { Agility kinetic boxing } \\
\text { test }\end{array}$} & Ability to mental perception & 0.523 & Statistically significant \\
\hline & Ability to focus attention & 0.702 & Statistically significant \\
\hline & Self confidence & 0.289 & Statistically significant \\
\hline & Ability to confront anxiety & 0.614 & Statistically significant \\
\hline & Ability to relax & 0.956 & Statistically significant \\
\hline & Motivation of athletic achievement & 0.571 & Statistically significant \\
\hline \multirow{6}{*}{$\begin{array}{l}\text { Attention focus meter } \\
\text { for boxer }\end{array}$} & Ability to mental perception & 0.821 & Statistically significant \\
\hline & Ability to focus attention & 0.785 & Statistically significant \\
\hline & Self confidence & 0.546 & Statistically significant \\
\hline & Ability to confront anxiety & 0.821 & Statistically significant \\
\hline & Ability to relax & 0.442 & Statistically significant \\
\hline & Motivation of athletic achievement & 0.903 & Statistically significant \\
\hline
\end{tabular}

** The tabular value of $(r)=(0.23)$, at the level of significance $(0.05)$, at the degree of freedom $(n-2)$.

It is noticed from the foregoing results presented in the above table that the correlation values calculated for the dimension of mental perception and boxing motor skills were greater than the tabular value, as the values between each skill were as follows: Attention concentration test for boxers with a correlation value (0.456), which is greater than the tabular value. This indicates that there is a correlation between the ability to mental perception and the skill of measuring attention concentration of boxers, as for the test of strength flexibility of the muscles of the arms by boxing until fatigue, the correlation value was $(0.714)$, which is also greater than the tabular value, this indicates a significant correlation with ability on the perception, as for the test of the kinetic speed of the two arms of a boxing, the correlation value was $(0.523)$, which is also greater than the tabular value, which indicates a correlation with the ability to visualize mental, and the test of agility in boxing was with a correlation value of 
(0.821), which is also greater From tabular, indicating an association with the ability to mental perception.

In terms to the values between each skill with the test of the ability to focus attention, the correlation value was (0.789), which is greater than the tabular value, and this indicates that there is a correlation between the ability to focus attention and the skill of the motor compatibility test, and with regard to the strength-flexion test of the muscles of the arms from boxing to fatigue, the correlation value was (0.259), which is greater than the tabular value, which indicates the existence of a significant correlation with the ability to focus attention. As for the kinetic test of the two arms in boxing, the correlation value was $(0.702)$, which is greater than the tabular value, which indicates the existence of Correlation with the ability to focus attention, and with regard to the boxing agility test, the correlation value was (0.785), which is greater than the tabular value, which indicates an association with the ability to focus attention.

As for the values between each skill with the test of self-confidence, they were as follows: With the test of concentration measurement of attention for boxers with a correlation value of (0.758), which is greater than the tabular value, this indicates the existence of a correlation between self-confidence and the skill of measuring attention concentration of boxers, and with the test of muscle strength extension Boxing arms up to fatigue correlation value (0.811), which is greater than the tabular value, which indicates a significant correlation with self-confidence, and with a motor velocity test with a correlation value (0.289), which is greater than the tabular value, which indicates a correlation with self-confidence, And with the boxing agility test with a correlation value (0.546), which is greater than the tabular value, which indicates a correlation with self-confidence.

With regard to the values with each skill with the ability to confront anxiety test, they were as follows: with the motor compatibility test with a correlation value of $(0.903)$ which is greater than the tabular value, this indicates the existence of a correlation between the ability to face anxiety and the motor compatibility test, and with the elongation test. The strength of the boxing arm muscles until fatigue with a correlation value of $(0.870)$, which is greater than the table value, which indicates a correlation with the ability to face anxiety, and with the motor velocity test with a correlation value of $(0.614)$, which is greater than the tabular value, which indicates the presence of a correlation With the ability to face anxiety, and with the motor agility test with a correlation value of (0.821), which is greater than the tabular value, which indicates an association with the ability to confront anxiety.

As for the values between each skill with the ability to relax test are as follows: with the motor compatibility test with a correlation value of $(0.751)$, which is greater than the tabular value, this indicates a correlation between the ability to relax and the skill of loco motor adaptation, with the test of strength elongation of the muscles of the arms by boxing until fatigue with a value of Correlation (0.524), which is also greater than the tabular value, which indicates a significant correlation with the ability to relax. With the kinetic velocity test with a correlation value of (0.956), it is also greater than the tabular value, which indicates a correlation with the ability to relax. With the kinetic agility test with a correlation value of (0.442), it is also greater than the tabular, indicating an association with the ability to relax.

In terms of the values between each skill with the athletic achievement motivation test are as follows: with the kinematic test with a correlation value of $(0.821)$, which is greater than the tabular value, this indicates a correlation between athletic achievement motivation and the kinematic test correlation (0.702), which is also greater than the tabular value, which indicates the existence of a significant correlation with motivation for achievement. With the kinematic velocity test, with a correlation value of $(0.571)$, which is also greater than the tabular, indicating a correlation with the motivation of achievement. With the kinetic agility test with a correlation value of (0.903), which is also greater than the tabular, which indicates a correlation with the motivation for athletic achievement.

Through the results of the previous table, it is evident that there are significant correlational relationships between the dimensions of psychological skills and some special motor skills, the researcher attributes this to the fact that the more the athlete develops his psychological skills, the kinetic accuracy of boxing develops.

Focusing attention also has an important role in boxing, as it is necessary in the stages of sports construction to constantly fix the components of information, this is done through various methods with practical requirements and associated with repetition, which require the athlete to focus and be able to restore memory, and is developed during the training process by Focused attention to solving sports duties, whether in training or competition, the attention of the athlete must be focused through a clear explanation, and attention must be developed in order to obtain stability and develop attention in boxers.

This is in addition to the fact that the coach provides information on the way and the style of playing for the competitor by the coach provides and prepares reassurance for the positive psychological factor of the boxer, and the deep inhalation and exhalation have a positive effect on the psychological disorders and tensions that accompany the boxer, anxiety is not necessarily a hindrance to performance and effort during the fight, On the contrary, anxiety is facilitated in favor of sports performance, as performance gradually improves whenever the level of anxiety of the athlete rises, and up to a certain point, and if anxiety rises to a higher level than that point, this leads to performance disruption and a lower level. 


\section{Conclusions and recommendations}

The researcher reached the following results:

0 There is a positive significant relationship between the dimensions of psychological skills and the Attention Focus Scale Test.

0 There is a positive a positive significant relationship between the dimensions of psychological skills and the test of elongation of strength for the muscles of the arms by boxing until fatigue.

0 There is a positive significant relationship between the dimensions of psychological skills and agility kinetic boxing test.

0 There is a positive significant relationship between the dimensions of psychological skills and the agility test of advanced boxers.

\section{Recommendations}

According to the researcher's findings, the following recommendations were made:

1. Interest in the psychological aspect, being one of the basic requirements that affect the athletic performance of a boxer.

2. Conducting psychological measures for boxers, because of its importance in identifying their psychological levels in a way that enhances their level of skill performance.

3. Conducting similar research and studies of psychological skills and their relationship to basic skills and other sporting events.

4. Conducting periodic tests for boxers in successive periods to find out the true level of mastery of performance, physical fitness and knowledge of boxing motor skills.

\section{References}

0 Ahmed, Ashraf, (2004), Linear thinking and its relationship to some psychological skills and the level of skill performance of boxers, Assiut Journal of Physical Education Sciences and Arts, Assiut University, No.(9), Part 2.

0 Alhasani, Nareman, (2003), The effectiveness of mental training and motor rhythm on the level of performance of the front somersault skill on the jumping horse and emotional stability for female students, unpublished PhD dissertation, Suez Canal University, Suez, Egypt.

0 Allawi, Mohammed, (1998), Encyclopedia of Psychological tests for athletes, Cairo: Book Center for Publishing.

0 Anastasi, A., (1972), psychological testing, Macmillan, psychological testing and easement. Emile, Planchard, Paris.

0 Atowi, Abdullah, (2017), The Relationship of Some Psychological Skills to Competitive Behavior of Football Players, Field Study of some Teams of the M'sila Province, the Cubs Category, unpublished Master Thesis, University of Mohamed Boudiaf, M'sila, Algeria.

0 Crust L, \& Clough, PJ, (2005), Relationship between mental toughness and physical endurance, percept mot skills, Vol.100, No.(1).

0 Falchinili, Eanko, (1986), Modern Exercise for Boxer, Rome International Amateur Boxing Association, ARRTCLES OF Association and rules for International Competition and Tournaments, Edition A.I.B.A.

0 Fawzi, Ahmad, (2006), Principles of Sports Psychology, $1^{\text {st }}$ edition, Cairo: Arab Thought House.

0 Fourie. S. \& Portgieter, J.R, (2001), the nature of mental toughness in sport south Africa, journal for research in sport physical education and recreation, vol. 23, No.2.

0 Fulgham, A, (2004), Implementing a psychological skills training program in high school volleyball athletes, Un publish Phd Dissertation, Missouri western state University, U.S.A.

0 Gordon, Sandy, (2004), Mood and Performance relationship among athletes at the world student games basketball competition, journal of sports behavior, Vol.24, No.(2).

0 Gould, D., Dieffenbach , K., \& Moffett, (2002), A Psychological characteristics and their development in Olympic champion, journal of applied sport psychology, Vol.17.

0 Guidetti, L., Musulin, A., Baldari, C., (2002), Physiological factors in middleweight boxing performance, J. Sports Med Phys Fitness, 42,309-14.

o Hayley, Merrett, (2004), Volleyball Mental Toughness- How to spark that volley ball fire in your athletes, Ezine article, U.S.A.

0 James, R. Morrow, Jr. Allen, W. Jakson. James, G. Dale, P. Mood, (2002) Measurement and Evaluation in Human Performance, 2thed. U.S.A. 
$0 \quad$ Khasky, A. \& Smith, J.C., (1999), Stress relaxation states and creativity, Perceptual and Motor skills, Vol.88, No.(2).

o Lefkowits, John, David, R., Mc Duff, Corina, Riismandel, (2003), Mental toughness training manual for soccer, Article Sports Dynamics, United Kingdom.

0 Loehr, James, (1994), the new toughness training for sports new York, penguin Books, U.S.A.

0 Lowther, James, (2002), Self- Efficacy and psychological skills during the amputee soccer world cup Athletic insight the online, journal of sport Psychology, Vol4, No.(2).

0 Middleton, Simon, Herb, W., Marsh, Andrew, Martin, J., Garry, Richards Perry, Clark, (2004), Discovering Mental toughness: A Qualitative study of mental toughness elite athletes, Self-research conference, selfconcept, Motivation and identity: where to form here, Berlin, Germany.

o Nashwan, Nashwan \& Arab, Mohammed, (2017), Sports Psychology, Amman: Dar alhamed publications.

0 Nashwan, Nashwan \& Dalala'ah, Mohammed, (2020), The effect of a mental training program in developing the focus and shifting attention of physical education teachers, a pilot study in the governorate of Irbid, Research Journal, No.(35), London Center for Research, Studies and Consulting.

0 Nashwan, Nashwan, (2010), Art of sport and health, Amman: Dar alhamed publications.

0 Nashwan, Nashwan, (2018), Boxing, Amman: Dijlah for publications.

0 Pedhazur, E. \& Schmelkin, L. (1991) Measurement, Design, and Analysis: An integrated approach, Hillslada, NJ: Lawernce Erlbum.

0 Porter, K., (2003), The mental athlete Champaign, Human Kinetics.

$0 \quad$ Pritchard, Keith, (2002), Goal Setting and Soccer Performance, senior provincial coach, U.S.A.

o Ray, Jolly, (2003), Mental toughness, Level III Hockey coaching course Karnataka stat Hochey, Association Bangalors.

$0 \quad$ Schmidt, R., \& Wrisberg, C., (2008). Motor Learning and Performance A situation-Based Learning Approach, $4^{\text {th }}$ Edition, Human Kinetics.

0 Sellars, Chris, (1997), Building self-confidence, coachwise publish. England.

0 Stevens, J. (2002), Applied Multivariate Statistics for the social Science, (4th ed.). Hillslada, NJ: Lawrence Erlbum

0 Thomas, R. \& fogarty, G., (1997), Training psychological skills in golf and the role of individual differences in cognitive formation, Research gate. 